\title{
ANKA-STATUS OF THE 2.5 GeV SYNCHROTRON LIGHT SOURCE AT FORSCHUNGSZENTRUM KARLSRUHE
}

\author{
D.Einfeld, A. Hagestedt ${ }^{1}$, E.Huttel, A.Krüssel, H.O.Moser, F.Perez ${ }^{2}$, M.Plesko ${ }^{3}$, \\ R.Rossmanith, J.Schaper, R. Simon, R.Steininger, D.Tommasini ${ }^{4}$, S.Voigt \\ Forschungszentrum Karlsruhe, POB 3640, D-76021 Karlsruhe, Germany \\ ${ }^{1}$ Fachhochschule Ostfriesland, Constantiapl. 4, D-26723 Emden,Germany \\ ${ }^{2}$ Lab. Sincrotro Barcelona-IFAE, Campus UAB, E-08193 Bellaterra, Spain \\ 3 J.Stefan Institute, Jamova 39, SLO-1001 Ljubljana,Slovenia \\ ${ }^{4}$ Sincrotrone Trieste, Padriciano 99, I-34012 Trieste, Italy
}

\section{Abstract}

ANKA, a $2.5 \mathrm{GeV}$ synchrotron light source will be built within the next three years at the Research Centre Karlsruhe, Germany. This source is dedicated to the fabrication of microstructures (LIGA-technique) and X-ray analysis. With four double-DBA structures, a magnetic field of $1.5 \mathrm{~T}$ and a circumference of $110.4 \mathrm{~m}$, an emittance of $39 \mathrm{~nm} \cdot \mathrm{rad}$ can be reached. ANKA has four long $(6 \mathrm{~m})$ straight sections for the installation of insertion devices. Additional four short (2.2 m) straight sections host the injection scheme, four ELETTRA-type cavities (two cavities per section) and one short insertion device. The $\mathrm{RF}$ power will be provided by two $250 \mathrm{~kW}$ klystron. The pre-acceleration will be done with a $22-50 \mathrm{MeV}$ linac or microtron. As injector a $500 \mathrm{MeV}$ booster synchrotron with a repetion rate of 3 to $10 \mathrm{~Hz}$ is foreseen. The ramping from $0.5 \mathrm{GeV}$ to $2.5 \mathrm{GeV}$ will be done in around one minute.Eleven out of thirty-two available bending magnet radiation ports will be equipped with beam lines in the first phase.

\section{INTRODUCTION}

Fabrication of microstructures by X-ray deep lithography (XRDL), galvanoforming, and plastic molding (German acronym LIGA) has made its way from Forschungszentrum Karlsruhe to many labs throughout the world. ANKA is designed to satisfy the needs of XRDL as well as of X-ray analysis, in particular, of microstructures. Industrial demand of service in both fields will play a major role for ANKA [1]. After the approval of ANKA in March 1996 a redesign of the storage ring has been done and the design of the main components has been finished. At present, a call for tender for the main components (injector, magnets, power supplies, vacuum-system, and rf-system) is under way and it is assumed that the first contracts for the production of some components can be placed in June 1997. According to the time schedule the first beam should be stored at the end of 1999 .

\section{LATTICE OF THE ANKA STORAGE RING}

As mentioned in earlier papers [2],[3], the lattice of ANKA is a double DBA-structure with a fourfold symmetry. The leading design principles were to build a light source which
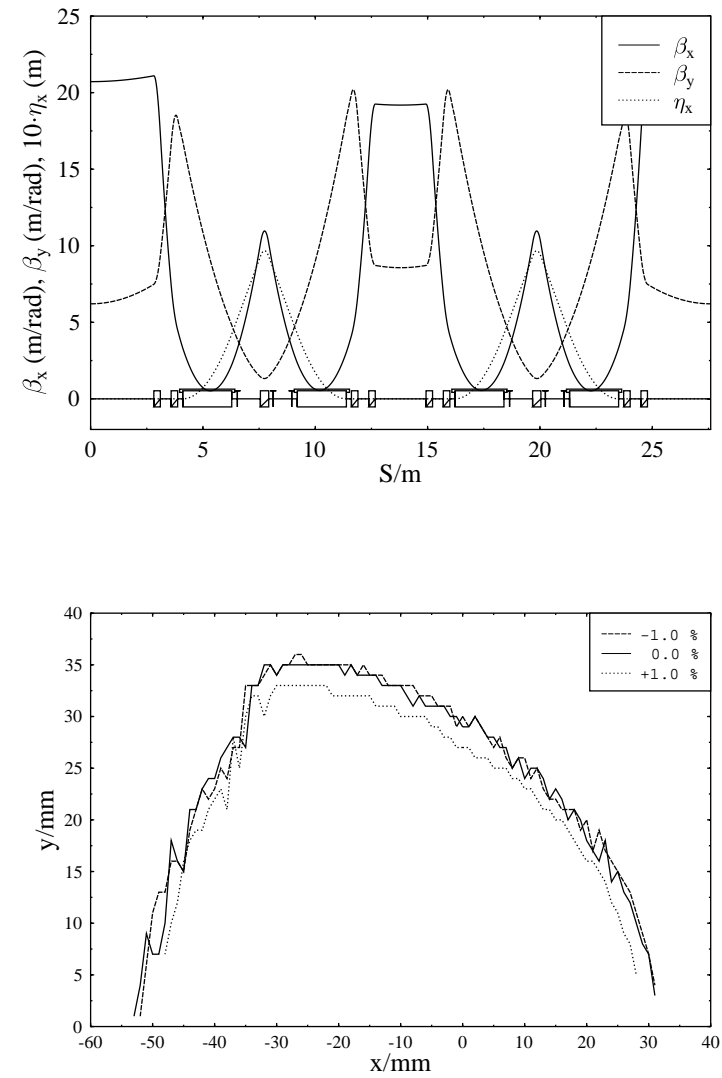

Figure 1: Behaviour of the machine functions within one quadrant of the ANKA storage ring: a) Upper figure: optics A with achromatic arcs, b) Lower figure: dynamical aperture of the ring.

is relatively small and has a low emittance; two conditions which are usually in contradiction. The original design contained only four straight sections of $5.6 \mathrm{~m}$ length each, one of which was used up for injection. To get more space for insertion devices, a redesign was made, increasing the circumference to $110.4 \mathrm{~m}$. ANKA now has four long straight sections $(6 \mathrm{~m})$ and four short straight sections $(2.2 \mathrm{~m})$. The layout of the storage ring is presented in fig. 2. The long straight sections are foreseen for insertion devices with the possibility to insert some more quadrupoles for getting a mini-beta section [4] in a later stage. The short straight sections will be used for the injection, for the in- 
Table 1: Main parameters of ANKA for both optics. * Upgrading at a later time.

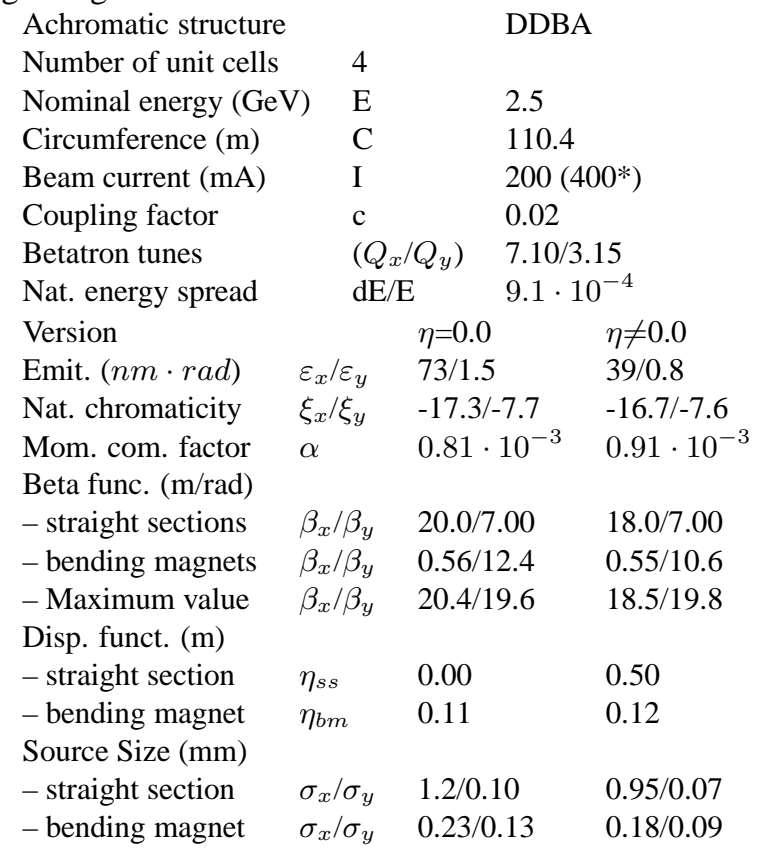

stallation of the four rf-cavities (two cavities in one section) and a short insertion device.

The machine functions within one quadrant are presented in fig.1. At the working point $Q_{x}=7.10 / Q_{y}=$ 3.15 the conventional DBA-lattice (optics A - fig. 1a) results in an emittance of $73.4 \mathrm{~nm} \cdot \mathrm{rad}$. By decreasing the strength of the quadrupole within the dispersive section one gets an optics with a distributed dispersion function (optics B). The minimum of the dispersion is now in the bending magnets, which leads to an emittance of $39 \mathrm{~nm} \cdot \mathrm{rad}$. The lattice can be shifted from one optics to another by keeping the working point constant. Because the dynamic aperture is larger for optics A (presented in fig 1b) than for optics $\mathrm{B}$, it is planned to accumulate the beam and ramp the energy from $500 \mathrm{MeV}$ to $2.5 \mathrm{GeV}$ with optics A and switch to optics B at nominal energy. The main parameters for both structures are given in table 1.

\section{COMPONENTS OF THE STORAGE RING ANKA}

\subsection{Magnets}

The first design of the ANKA magnets has been presented at the EPAC 96 [5]. During the redesign of the bending magnets the pole profile has been changed in order to get to higher fields. Now it should be possible to run the magnets with a maximum field of $1.65 \mathrm{~T}$. The nominal field is $1.5 \mathrm{~T}$. For the quadrupoles and the sextupoles only the pole shape has been changed in order to have parallel coils, which should be cheaper for the production.

\subsection{Vacuum System}

The vacuum chamber with a height of $32 \mathrm{~mm}$ and a width of $70 \mathrm{~mm}$ will be made of stainless steel. An in situ bake out is not foreseen. Most of the synchrotron radiation will be absorbed by discrete absorbers ( two per bending magnet) in ante chambers. Here $500 \mathrm{l} / \mathrm{s}$ and $300 \mathrm{l} / \mathrm{s}$ diode pumps will be installed. The pumping will be done with a total nominal pumping speed of $18800 \mathrm{l} / \mathrm{s}$ and $13000 \mathrm{l} / \mathrm{s}$, respectively, at $10^{-9}$ mbar. Pressure profile calculations show that the foreseen pumping speed should be sufficient to obtain a pressure of $3 \cdot 10^{-9}$ mbar, necessary to get a lifetime of more than $12 \mathrm{~h}$. More details of the vacuum system are presented in a seperated paper of this conference [6].

\subsection{RF System}

The rf system consists of four cavities and two $250 \mathrm{~kW}$ klystrons. With an installation of a rf power of $500 \mathrm{~kW}$ it is possible to accelerate a beam of $400 \mathrm{~mA}$ with an overall cavity voltage of $3.2 \mathrm{MV}$. This leads to an overvoltage factor of $q=5$ with an energy acceptance of $2 \%$ for the klystrons. A power supply with $50 \mathrm{kV}$ and a current of 16 $\mathrm{A}$ is needed. Within this scheme the input has to stand a power of $120 \mathrm{~kW}$. The intention is to use the cavities and the input couplers designed at ELETTRA[7]. A test performed recently at DESY showed that the ELETTRA input coupler can withstand a power of more than $130 \mathrm{~kW}$.

\subsection{Injector}

The injector at ANKA consists of a $20-50 \mathrm{MeV}$ preaccelerator, a $500 \mathrm{MeV}$ booster synchrotron and the two transfer lines. As preaccelerator a microtron or linac can be used. For the booster synchrotron we investigated both a weak focusing and a strong focusing machine. Both types have some advantage and disadvantages. They are discussed in a separated paper [8] at this conference. For the ANKA project it is foreseen to buy the whole injector as a turn key machine from industry.

\subsection{Control System}

The design of the ANKA control system [9] is based on standard industry components. A minimum number of different hardware interfaces will be allowed. PCs are used as consoles and servers. The operating system is Windows NT. Graphical applications will be implemented in Java in order to fully benefit from Internet and WWW products and technologies. Communications, run-time databases and objects will be supported by the control system platform TACO [10] that has been developed by the ESRF. Currently, several field buses, which will connect PCs to controlled equipment, are being investigated. As of now, preference is given to LonWorks. Both TACO and LonWorks have been evaluated and proven to meet the needs of ANKA. 


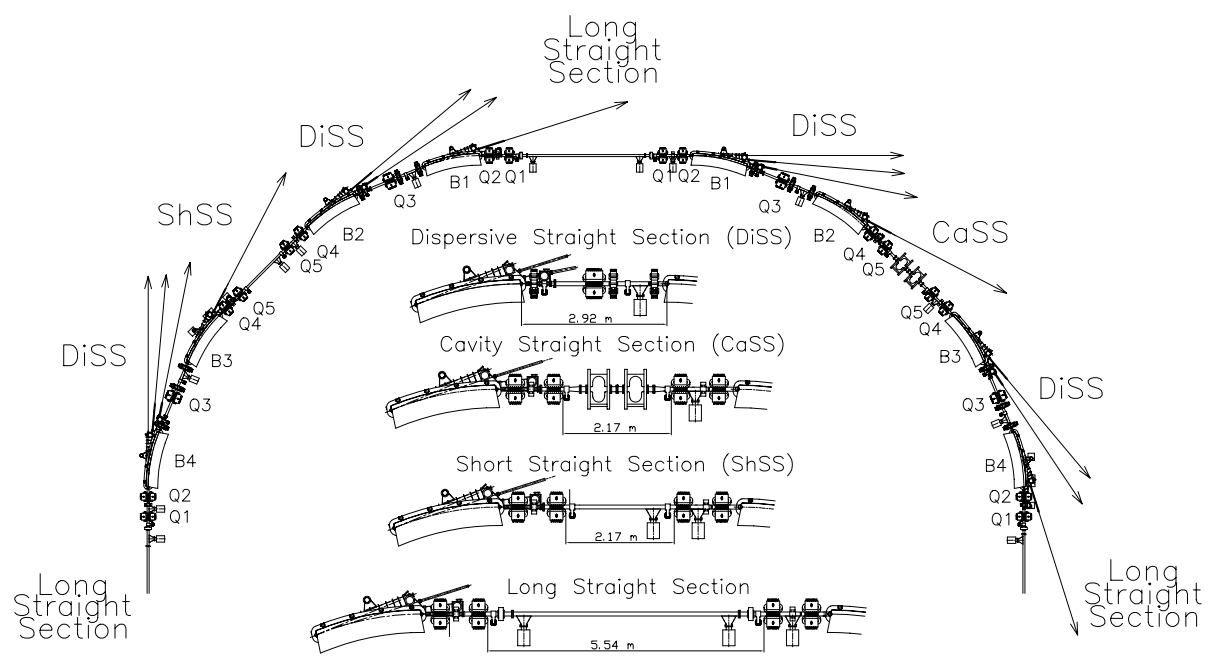

Figure 2: Layout of half of the storage ring ANKA.

Table 2: The beamlines to be built in first phase of ANKA

\begin{tabular}{|c|c|c|}
\hline & Method & Industrial application \\
\hline $1-3$ & $\begin{array}{l}\text { X-ray deep litho- } \\
\text { graphy }\end{array}$ & Microfabrication \\
\hline 4 & $\begin{array}{l}\text { Absorption, diffrac- } \\
\text { tion }\end{array}$ & $\begin{array}{l}\text { Catalysts, chemical analysis, } \\
\text { electrochemistry }\end{array}$ \\
\hline 5 & Diffraction & $\begin{array}{l}\text { Macromolecular crystallogra- } \\
\text { phy, powder \& single crystal } \\
\text { diffraction }\end{array}$ \\
\hline 6 & $\begin{array}{l}\text { XUV spectromi- } \\
\text { croscopy }\end{array}$ & $\begin{array}{l}\text { Mesoscale microscopy, ab- } \\
\text { sorption spectroscopy of light } \\
\text { elements }\end{array}$ \\
\hline 7 & $\begin{array}{l}\text { (F)IR spectro- \& } \\
\text { micro-scopy }\end{array}$ & Chemical analysis \\
\hline 8 & Fluorescence & Trace analysis (wafer) \\
\hline 9 & Topography & Crystal quality (wafer) \\
\hline 10 & $\begin{array}{l}\text { SAXS, Tomogra- } \\
\text { phy }\end{array}$ & $\begin{array}{l}\text { Polymers, morphology of ir- } \\
\text { regular structures }\end{array}$ \\
\hline 11 & Roentgenography & $\begin{array}{l}\text { Stress \& strain, morphology, } \\
\text { texture }\end{array}$ \\
\hline
\end{tabular}

\subsection{Beamlines}

11 beamlines, as presented in table 2, are planned to be built in the first phase. They cover X-ray deep lithography in the framework of LIGA technology and related methods in microfabrication, and include important analytical methods.

\section{REFERENCES}

[1] H.O. Moser, D. Einfeld, R.Steininger, Vorschlag zum Bau einer Synchrotronstrahlungsquelle (ANKA) im Forschungszentrum Karlsruhe zur Foerderung der industriellen Nutzung von Mikrofertigung und Analytikverfahren, Forschungszentrum Karlsruhe, 22 September 1995
[2] H.O. Moser et al, ANKA, a Synchrotron Light Source for Microstructure Fabrication and Analysis, Proceedings PAC 95, May 1-5, Dallas, Texas

[3] D.Einfeld, J.Schaper, F.Iazzourene, H.O. Moser, Lattice and Dynamical Behavior of the Light Source ANKA, Proceedings EPAC 96, Sitges (Barcelona), 10-14 june 1996

[4] U.Bandow, D.Einfeld, T.Hezel, H.O.Moser, R.Rossmanith, J.Schaper, Calculation of the Dynamic Aperture in the ANKA Storage Ring with a High-field Wavelength Shifter, Proceedings EPAC 96, Sitges (Barcelona), 10-14 June 1996

[5] D.Einfeld, A.Kruessel, D.Tommasini, Magnet Design for the Synchrotron Light Source ANKA, Proceedings EPAC 96, Sitges (Barcelona), 10-14 June 1996

[6] E.Huttel, D.Einfeld,The Vacuum System of the Synchrotron light Source ANKA, this conference

[7] ELETTRA, Conceptional Design Report, Sincrotrone Trieste, Padriciano 99, I 34012 Trieste

[8] D.Einfeld, F. Perez, R.Rossmanith, R.Walther, The ANKA Booster Synchrotron, this conference

[9] S. Avsec, B. Jeram, G. Mavric, M. Plesko, M. Smolej, Designing the Control System of ANKA, this conference.

[10] A. Goetz et al., TACO: An object oriented system for PC's running Linux, Windows/NT, OS-9, LynxOS or VxWorks, presented at the PCs and Particle Accelerator Control (PCaPAC) Workshop, DESY Hamburg, 1996. 